\title{
Entre dos jurisdicciones. La labor de los jueces comisionados y la desarticulación de las redes locales de poder político. Santa Fe de la Vera Cruz en el siglo XVIII
}

\author{
Between two jurisdictions. The work of commissioned judges \\ and the disarticulation of local networks of political power. \\ Santa Fe de la Vera Cruz in the 18th century \\ María Celeste Forconi \\ CEHISO \\ Universidad Nacional de Rosario-ARGENTINA \\ mcforconi@gmail.com
}

\section{Resumen}

Este artículo se propone contribuir a la discusión sobre el fortalecimiento del absolutismo en el contexto del ascenso de la casa de Borbón a la corona española. Desde una perspectiva americana, la investigación hace foco en la figura de los jueces comisionados, en la ciudad de Santa Fe de la Vera Cruz, perteneciente a la jurisdicción de la gobernación de Buenos Aires, durante la primera mitad del siglo XVIII. Estos magistrados, en relación directa con el gobernador y su brazo de confianza en la ciudad, se constituyeron en un instrumento cuyo objetivo fue la desarticulación de las redes locales de poder político. El juez comisionado y su acción judicial nos permiten poner a prueba la imagen de los enfoques historiográficos sobre "el estado moderno absoluto", como un camino lineal de fortalecimiento del absolutismo en desmedro de las autonomías de la administración colonial americana.

Palabras clave: Jueces comisionados-Siglo XVIII-Santa Fe de la Vera Cruz- Poder Real-autonomías locales.

\begin{abstract}
This article aims to contribute to the discussion on the strengthening of absolutism in the context of the rise of the Bourbon house to the Spanish crown. From an American perspective, the investigation focuses on the figure of commissioned judges, in the city of Santa Fe de la Vera Cruz, belonging to the jurisdiction of the Buenos Aires governorate, during the first half of the 18th century. These magistrates, in direct relationship with the governor and his trust arm in the city, became an instrument whose objective was the disarticulation of local networks of political power. The commissioned judge and his judicial action allow us to test the image of historiographical approaches to "the absolute modern state", as a linear path of strengthening absolutism to the detriment of the autonomies of the American colonial administration.
\end{abstract}


Key words: Commissioned judges- 18th century- Santa Fe de la Vera Cruz- Real Power-local autonomies.

Recibido: 30 de julio de 2020 - Aceptado: 14 de noviembre de 2020

\section{Introducción}

El giro planteado por la Nueva Historia Política incorporó una mirada social de la política, ampliando aquello considerado político y los agentes que intervienen en este campo. Para esta historia social de la política y el poder, la naturaleza de lo que se considera "lo político" es múltiple y mucho más compleja. Los trabajos enmarcados en este enfoque se han centrado, para América Latina, en el estudio de los períodos revolucionarios y posrevolucionario del sigloXIX, relegando ámbitos y períodos considerados menos importantes, en función de una perspectiva preocupada por la conformación de los Estados Nacionales. El abordaje de lo político en las sociedades de Antiguo Régimen se nos presenta, así, como un desafío que intenta rescatar la fisonomía política de fenómenos históricos apartados de las preocupaciones de la historia política tradicional. El corrimiento de la mirada estatalista del pasado se vio fortalecida por las producciones historiográficas nacidas del diálogo entre la historia política y la historia jurídica y de la justicia. Una historiografía que comprende la estrecha y necesaria conexión entre la organización política y la comprensión de su ordenamiento jurídico (Barriera, 2014; Clavero, 1993; Garriga, 2012). Los trabajos pioneros de Bartolomé Clavero y Antonio Manuel Hespanha propusieron pensar el Antiguo Régimen como un universo político plural, con diversos niveles de normatividad social y con multiplicidad de instrumentos, procedimientos y recursos mediante los cuales se lograba la aceptación voluntaria o no de las normas. Esta nueva propuesta se constituyó en uno de los insumos más importantes de la corriente historiográfica jurisdiccionalista (Clavero, 1981, 1991; Hespanha, 1989, 1994).

La clave en la construcción del poder político en el Antiguo Régimen estaba estrechamente ligada al derecho, puesto que, el ejercicio del poder político fue la facultad de decir derecho y de administrar justicia. Esta indisoluble relación entre política y justicia, fue la esencia de la cultura jurisdiccionalista del Antiguo Régimen (Garriga, 2004). La ciudad fue el lugar por excelencia de la política y la justicia, constituyéndose el acto jurídico que dio existencia y organización a un grupo humano, diseñando una peculiar modalidad de apropiación y construcción del espacio. El gobierno de la ciudad se conformó en un cuerpo colegiado, la reunión de vecinos en el cabildo, que administraba el "bien común" y “buen orden". Velar por el orden y bien de todos suponía el ejercicio del atributo más importante de la majestad, la justicia y su fin fue la conservación del equilibrio entre los distintos cuerpos que componían la monarquía y sus respectivos ordenamientos jurídicos. La potestad real fue delegada en cuerpos colegiados, $y$ a veces en algunos funcionarios ${ }^{1}$ individuales, encargados de hacer "juicio y justicia” y que se configuraron en entidades administrativas con altos grados de autonomía. Por lo tanto, la función 
principal del poder político fue el ejercicio de la justicia que suponía custodiar y legitimar el orden social, resolviendo los conflictos entre diferentes esferas de intereses. "No sorprenderá que el conflicto formase parte de la fisiología (y no de la patología) de los cuerpos políticos en el Antiguo Régimen, siempre necesitados de una instancia armonizadora que, dando a cada uno lo que le correspondiese, garantizara la permanencia del orden jurídico en su conjunto" (Garriga, 2004: 39).

En la presente investigación se analizan dos coyunturas de tensión entre los mandatos que el poder real puso en manos de sus ministros y los intereses de estos grupos de poder locales que había logrado significativos niveles de autonomía. A lo largo de los siglos el carácter polisinodial en la administración del gobierno y la justicia fue ganando en autonomía respecto del poder real. Por esa razón, una de las estrategias de los diferentes monarcas -desde los reyes católicos- para recuperar el control político de sus territorios fue el recurso a las comisiones judiciales. Un dispositivo que intentó poner freno al avance de las elites locales (Cárceles de Gea, 1995; Gómez González, 2011; Molina, 2012, 2014; Albornoz Vásquez, 2015; Enríquez, 2016)el fraude adquiere una conceptualización de acuerdo con los criterios contributivos en función de los cuales los monarcas modernos gestionan el fisco. Como consecuencia, la transgresión fiscal se convierte en el impulsor de las reformas administrativas por cuanto que de su control depende el triunfo de los requerimientos fiscalizadores de la monarquía y con él la conformación de un fisco expresión de las «necesidades públicas»","container-title":"Studia Historica. Historia Moderna","ISSN":"0213-2079","langu
age":"spa","page":"155-175","title":"Del juez de comisión al comisario real (1632-1643. El foco de este trabajo está puesto en la figura de los jueces comisionados, magistrados que cumplieron el rol de bisagra entre los poderes locales y las instancias superiores de gobierno. El objetivo de su designación no se limitaba al ejercicio de la justicia, sino que, para hacerlo, fue necesaria la desarticulación de las redes locales de poder político. Durante la primera mitad del siglo XVIII el cabildo santafesino fue hegemonizado por una configuración familiar que articuló su participación en el ámbito político local con sus negocios comerciales, en ocasiones ilegítimos. Por otro lado, las dos comisiones judiciales que se analizan contribuyen a refutar la idea del debilitamiento de los cuerpos colegiados frente al avance del absolutismo Monárquico en el siglo XVIII. Los nuevos enfoques jurisdiccionalitas consideran que la centralización política de las monarquías modernas formó parte de un discurso prescriptivo, del deber ser, más que la descripción de las prácticas efectivas (Sanjurjo de Driollet, 2016; Garriga, 2012; Agüero, 2005) Estos agentes comisionados y sus acciones judiciales nos permiten poner a prueba la imagen de los enfoques historiográficos sobre "el estado moderno absoluto", como un camino lineal de fortalecimiento del absolutismo en desmedro de las autonomías de la administración colonial americana. Por otra parte, nos acerca a una comprensión más relacional del poder.

Los cuerpos colegiados que rigieron las ciudades se conformaron por elites afirmadas localmente por una política de vínculos personales, de parentesco, de clientelismo, vecindad, paisanaje, entre otros 
(Imízcoz 1996, 2004; Forconi, 2013; Moutoukias, 1988, 1995). Estos tejidos sociales conectaban a los grupos dominantes asegurando la articulación entre los ámbitos políticos y económicos, experimentando su propia dinámica de poder polivalentes, es decir, en el ejercicio de varias funciones, políticas, económicas, intelectuales y eclesiásticas (Moutoukias, 2000). Por ello, la incorporación de una mirada social a la historia política tuvo un fuerte impulso con los estudios de familia, que permitieron salir de las grandes figuras como exclusivos agentes políticos o de la mirada estructural - estatalista, para comprender lo político y el poder a partir de una concepción relacional, poniendo énfasis en los modos de ejercicio y en las dinámicas del poder político en sociedades de Antiguo Régimen. Dentro de este campo la atención fue puesta sobre las familias de elite, por el lugar dominante que ocuparon en la dirección de los gobiernos locales “ya fuera por su capacidad económica, por su estatus, por su influencia en la vida política o por las funciones públicas que pudiera desempeñar, constituye un estrato que participa de una situación de privilegio en un marco geográfico determinado" (Ponce Leiva y Amadori, 2008: 12). La formación, comportamiento, reproducción y mecanismos de perpetuación de estos grupos en el poder fueron los tópicos más recurrentes en la producción historiográfica hispanoamericana colonial desde la década de 1970.

Las metodologías utilizadas por los estudios de familia fueron múltiples y variadas, van desde la genealogía clásica hasta los recientes análisis de redes ${ }^{2}$ y configuracional, ${ }^{3}$ pasando por la prosopografía, biografías familiares, personales o historias de vida. Por otra parte, los aportes de la epistemología constructivista sumaron a estos abordajes una mirada de mayor complejidad a las relaciones sociales. Permitieron entender las relaciones como una interacción entre las estructuras, la contingencia de los acontecimientos y las elecciones particulares de los individuos que conforman un grupo (Ceruti, 1998).

Los jueces comisionados estudiados en este trabajo desempeñaron sus funciones en la ciudad de Santa Fe de la Veracruz, una jurisdicción perteneciente a la gobernación del Río de la Plata en el virreinato de Perú. El hecho de que el espacio sea acotado no supone que el trabajo sea un estudio de caso, sino una reducción de escala. Este gesto metodológico, propuesto por la microhistoria, consiste en acceder a una visión general de determinado problema, a través de la puerta que abre un tema particular, es decir, invertir el punto de partida y aproximarse al todo desde lo particular (Barriera, 2002; Ginzburg, 1989). Esta mirada plantea una nueva relación entre lo micro y lo macro, tratándolos como distintos niveles de una misma realidad histórica y que presentan cada uno su lógica.

El contexto temporal en el que transcurren las tensiones que se analizan, tiene sus particularidades. Después de un inicio de siglo convulsionado por la guerra de sucesión española y el cambio dinástico, una vez finalizada la contienda sucesoria, se abrió una etapa de transformaciones en el gobierno de los territorios de la monarquía ${ }^{4}$. El objetivo del plan reformador borbónico fue el de recuperar el poder de la autoridad monárquica. Para ello se buscó agilizar la administración de la 
justicia, mejorar la defensa y reforzar el control económico-fiscal de los dominios americanos, muchos de ellos, del Caribe al Río de la Plata, a merced de potencias extranjeras (Birocco, 2011a, 2011b; Tarragó, 2006b, 2012). En este escenario, se encomendaron las investigaciones a dos vecinos santafecinos, una de ellas sobre el apoyo de algunos vecinos notables al líder de la revolución comunera del Paraguay. La otra, investigó una causa de contrabando que involucró a vecinos de la ciudad. El nexo común a ambas causas es la participación de miembros de una misma familia, que además, fue el grupo que logró hegemonizar el ámbito capitular durante la primera mitad del siglo XVIII.

Los fondos documentales sobre los cuales se realiza esta investigación corresponden, por una parte, al acervo obrante en el Archivo General de la Nación, del cual se trabajan dos casos de comercio ilícito. Uno de ellos, se reconstruye a partir de un cuerpo epistolar formado por la correspondencia entre el Gobernador Bruno Mauricio de Zavala, el juez comisionado y los comerciantes santafesinos asociados al líder comunero, Joseph de Antequera. El otro documento corresponde a un expediente judicial sobre comercio ilícito de mulas entre vecinos de Santa Fe y portugueses de Colonia del Sacramento, iniciada en el ocaso de la gobernación de Miguel de Salcedo y Sierralta (1734-1742). De esta última investigación se abrieron tres procesos judiciales, uno al transportador de la hacienda, otro a los propietarios de ella y por último, al juez comisionado para las otras dos causas, por la acusación de "sumaria defectuosa".
Asimismo, para la reconstrucción de los vínculos entre los agentes involucrados, se recurrieron a los archivos notariales, obrantes en el Departamento de Estudios Etnográficos y Coloniales de Santa Fe y a los registros eclesiásticos de la Catedral Metropolitana de Santa Fe. También se consultó el fondo de las actas capitulares del Cabildo de Santa Fe en el Archivo General de la Provincia de Santa Fe que permitió recuperar la participación en el ámbito capitular de los involucrados en los expedientes judiciales, para comprender cómo usaron de su influencia para su propia defensa.

\section{El juez comisionado}

La justicia de Antiguo Régimen se componía de dos tipos de jurisdicciones. La jurisdicción ordinaria que poseía cualquier magistrado por las facultades nativas de su empleo, como la que tenía un alcalde ordinario, un corregidor, un intendente y una Audiencia. O la jurisdicción delegada que era la que se ejercía por mandato o comisión de la justicia ordinaria, limitada a la causa puntual que comprehende la comisión, es decir, para cumplir con una tarea con un cierto grado de especificidad y temporalmente acotada (Gómez González, 2011; Zorraquín Becú, 1981; Girón Zúñiga, 2015). Por otra parte, como señala Albornoz Vásquez (2015) estos jueces de comisión no pertenecían a lo que se denominan jueces territoriales sino que, el territorio de ejercicio de la justicia quedaba delimitado por los espacios en que residían o se desplazaban las partes implicadas en el litigio. Los jueces delegados tenían la facultad "solamente para hacer información, prender los delincuentes, traerlos a las cárceles..." (Recopilación Leyes de Indias, lib. VII, tit. I ley III), embargar bienes y oficios, 
es decir, poner las causas en estado de sentencia. Una vez hecho esto, la vista de los autos, para la determinación de la sentencia, quedaba en manos de la autoridad superior que había delegado la potestad en el comisionado.

Los jueces delegados fueron de distinto tipo: comisionados, comisarios reales, jueces pesquisidores, ejecutores, su denominación dependía de la función que le era delegada en la comissio. Una de las primeras designaciones en comisión, desde los Reyes Católicos, fue para realizar la pesquisa y residencia de los alcaldes, regidores, gobernadores, corregidores; con un claro objetivo de control y disciplinamiento monárquico hacia las autoridades, los que cumplieron esta función fueron llamados, jueces de residencia (González Alonso, 2000). La figura del juez de comisión fue un recurso del poder real para superar los problemas intrínsecos a la colegialidad, como los altos grados de autonomía logrados por las elites locales, puesto que estos jueces delegados coyunturalmente podían estar por encima de las propias instituciones. El recurso de las comisiones tenía como objetivo frenar los excesos cometidos por las elites locales tanto en el manejo de la jurisdicción como en los negocios que realizaban al amparo de su poder jurisdiccional. El ramo de la administración en el cual más se utilizaron las comisiones fue el de la hacienda, justamente, para las investigaciones de fraudes fiscales (Gómez González, 2011: 32).

Sin embargo, las comisiones no sólo se limitaron a la justicia, también se otorgaron con funciones de policía, militares y de hacienda de carácter especial. Esta primera transformación fue introducida por el Conde Duque de Olivares para la persecución del fraude fiscal al servicio de millones. Los jueces asignados fueron llamados comisarios reales, convirtiendo la comissio en un instrumento de control fiscal al servicio del poder real (Cárceles de Gea, 1994, 1995)"ISBN":"97884-7793-268-0","language":"es","number-ofpages":"137","publisher":"Banco de España, Servicio de Estudios","publisher-place":"Madrid"," source":"Library of Congress ISBN","title":"Fraude y administración fiscal en Castilla: la Comisión de Millones (1632-1658. Además de las comisiones asociadas al gobierno y la hacienda Gómez González (2011) señala que también hubo otras que se relacionaron con diferentes funciones como el mantenimiento del orden público, el mando y la provisión de los ejércitos, encargo de mantener la provisión de trigo o la dirección de obras públicas, etc.

En el caso de América, la potestad de la comissio también provenía de la justicia ordinaria como alcaldes ordinarios, audiencias, gobernadores o virreyes. Si bien la caracterización de estas comisiones corresponde a la acepción más antigua de la figura del comisionado -como juez con competencias extraordinarias- a lo largo del siglo XVIII fueron mutando y ampliando sus atribuciones. A mediados de ese siglo se pasó de las comisiones con causas judiciales puntuales, con tiempo acotado y territorio delimitado por el litigio particular, a designar comisiones "asociadas con el desarrollo de tareas de baja magistratura rural pero ya no respecto de un asunto sino respecto de una unidad territorial" (Darío G. Barriera, 2012). Esta mutación de una justicia especial (jueces comisionados) hacia una justicia con unidad territorial (jueces territoriales) fue 
la respuesta a la creciente densidad demográfica que, por ejemplo, van adquiriendo las campañas rioplatenses en un contexto de expansión de la producción ganadera (Barriera, 2017; Barriera y Fradkin, 2014).

Otra característica que destacan los estudios sobre jueces comisionados es la elección de personas de "confianza" de la institución o del funcionario real que delegaba el poder. Esto significaba, la mayor parte de las veces, que se designaba a un hombre que no tuviera vinculación con la jurisdicción en la que tenía que desempeñar sus funciones (Cárceles de Gea, 1994: 172).

\section{Jueces comisionados para "lidiar con estos hombres que viven tan apartados de la razón y justicia"}

El ingreso de los Borbones a la corona española supuso el restablecimiento de equilibrios ${ }^{5}$ en la relación del rey con sus reinos, en la administración de la hacienda, el gobierno y la defensa. Uno de los dispositivos al que recurrieron fue el de los jueces comisionados para lograr una mayor eficacia en el control de las recaudaciones de la Real Hacienda. Como señala Cárceles de Gea "Aunque la existencia del juez comisionado encajaba en la estructura del régimen conciliar, no por ello dejaba de representar una alteración del statu quo interno de las ciudades" (1994: 156).

La problemática de la justicia delegada -como instrumento de control, como límite a las autonomías de las elites de poder en el manejo del gobierno y como extensión del brazo Real en sus dominios de ultramar-se analiza a través del mirador que ofrecen dos casos judiciales. Los expedientes judiciales y documentos epistolares seleccionados para este estudio corresponden a fraudes a la Real Hacienda. Uno de ellos se inició en 1725 con una comisión otorgada por el virrey José de Armendáriz, marqués de Castelfuerte (1724-1736), al tesorero de la ciudad de Santa Fe, Francisco de Bracamonte. La investigación fue sobre comercio ilícito y fomento económico de algunos vecinos de Santa Fe al líder del movimiento comunero del Paraguay, José de Antequera y Castro. El otro caso se inició en 1740, cuando el gobernador Miguel de Salcedo y Sierralta otorgó comisión al regidor decano Juan de Zevallos, para una investigación por contrabando de hacienda con Colonia del Sacramento.

Los dos comisionados, Juan de Zevallos y Francisco de Bracamonte, fueron vecinos prestigiosos de Santa Fe que, sin embargo, no establecieron vinculación con los grupos de poder locales. Zevallos era el regidor decano de la ciudad, una figura muy particular con muy pocos vínculo en la comunidad santafesina. Ignacio de Barrenechea, acusados en una causa sobre contrabando investigada por el regidor, describe que "el dicho Don Juan de Zevallos actuante de la expresada sumaria, esta enemistado no solo conmigo y mi familia sino con la mayor parte o toda de esta Vecindad"6 . El otro comisionado, Francisco de Bracamonte fue tesorero de la Real Hacienda en Santa Fe durante veintiún años. Se vinculó a una familia de gran notabilidad a través de un matrimonio, los Martínez del Monje que, además, fueron los acusados en los casos judiciales estudiados. Sin embargo, cuando se inicia en su función como comisionado ese vínculo se había roto por "haberse 
disuelto el matrimonio sin hijos entre la persona del sarx.to mayor Don. Francisco Bracamonte regidor y alcalde ordinario y la persona de Doña Francisca Martínez del Monje hermana difunta del dicho Alférez Real por cuya Razón terminó el parentesco"7 . Pero también, Bracamonte se enemistó con la familia de su esposa por una disputa sobre los bienes del matrimonio a la muerte de Francisca ${ }^{8}$.

Una de las características más importantes sobre el juez comisionado, la cercanía a quién delegaba el poder y la lejanía de los justiciables, presentó algunas particularidades en las investigaciones seleccionadas para este estudio. En este sentido, es interesante reflexionar sobre la manera en que opera la función distancia en la resolución de conflictos, como contrapesos entre las autonomías locales y las políticas reformistas dieciochescas. En los casos tomados para el presente estudio, la distancia entre los justiciables y los jueces no fue del tipo física (geográfica o territorial), tampoco cultural (refiriendo al dominio de saberes específicos), sino un distanciamiento social. Este último rasgo de la función distancia refiere a los lazos (de parentesco biológico y ritual, de paisanaje, comerciales, etc.) entre los jueces y las poblaciones locales, que podían suscitar conflictos de intereses en la búsqueda del bien común (Barriera, 2013). Como se indicó, en los casos estudiados para este artículo, el distanciamiento territorial no fue condición necesaria de distanciamiento social. La combinación de cercanía territorial y distancia social probablemente se constituyó en un factor de peso para la elección de estas personas en una función judicial especial. Esta cercanía geográfica del Juez aportaba un conocimiento del tejido relacional y las tramas de poder de las elites, que alguien ajeno a la ciudad no hubieran podido desentrañar rápidamente, y eran fundamentales a la hora de convocar a los testigos para llevar adelante la sumaria.

En ambas causas judiciales, tanto los alcaldes ordinarios como los involucrados en las actividades ilícitas pertenecían a los mismos grupos familiares, cuyo tronco principal fueron los Martínez del Monje y que hegemonizaron el poder en el cabildo durante la primera mitad del siglo XVIII. Las varas de primer y segundo voto de la ciudad de Santa Fe fueron ocupadas por miembro de este verdadero clan familiar en cuarenta ocasiones, mientras que las sesenta restantes no fueron monopolizadas por otro grupo familiar. Durante el mismo período, uno de sus miembros (Juan de Lacoizqueta) fue dos veces teniente de gobernador -justicia mayor-otro (Ignacio Martínez del Monje) ejerció como alférez real durante diecisiete años, y entre 1725 y 1749 Miguel Martínez del Monje fue propietario de una regiduría perpetua (Barriera y Forconi, 2015). El fundador de esta familia, Francisco Martínez del Monje, tuvo diez hijos, cinco de ellos siguieron la carrera eclesiástica y los otros cinco fueron quienes extendieron el entramado familiar. Los acusados e investigados por el comisionado Bracamonte en la causa sobre comercio ilícito y fomento a Joseph de Antequera, pertenecieron a los Martínez del Monje. Dos hermanos, el alférez real Ignacio Martínez del Monje y el regidor Miguel Martínez del Monje, el maestre de campo Juan Joseph de Lacoizqueta (sobrino de los dos anteriores), el alcalde provincial Antonio Márquez Montiel (suegro de Juan Joseph) e Ignacio Barrenechea (yerno de Ignacio M. del 
Monje). Este último, fue señalado como uno de los dueños del ganado comerciado ilícitamente con los portugueses en la causa investigada por el comisionado Juan de Zevallos (Forconi, 2016, 2019)frente a los intentos de los agentes borbónicos de imponer el poder real por encima de las autonomías locales. A través del examen de una causa judicial sobre comercio ilícito entre algunos vecinos santafesinos y Joseph de Antequera (líder de las Revoluciones Comuneras del Paraguay.

La preferencia por la justicia comisionada tuvo que ver, sin dudas, con la preeminente presencia de los acusados en el ámbito capitular. Como señalaba el jurista Castillo de Bobadilla, uno de los motivos para la designación de comisionados fueron "los delitos graves" y cuando en ellos estaban involucradas "personas muy poderosas" o "en los cuales se crea, y tenga por cierto, que las Justicias Ordinarias no tienen poder para castigarlo, y determinar, o porque ellos son culpados en ello, o negligentes en evitarlo, o en unirlos". (Castillo de Bobadilla, 1775: Lib. II, Cap. XXI, 788-789) ${ }^{9}$. La autonomía de las elites en el manejo político de la ciudad implicó comportamientos que fueron calificados como "tan absolutos, que ni aun la justicia quieren los domine, ni los Ministros ejecutores sele atrevan; todo lo quieren supeditar, que pudiera decir que casi, no quieren subordinarse ni aun al Rey"10 .

Además de su destacada presencia en la vida política de la ciudad, los vecinos involucrados en las causas investigadas fueron comerciantes que desarrollaron estas actividades, lícitas e ilícitas, bajo el amparo de la jurisdicción local que ellos mismos administraban. Como señaló
Moutoukias (1988) en su clásico estudio sobre el contrabando, la distinción entre comercio lícito e ilícito presenta dificultades, por la coincidencia entre las personas que lo practicaban, las rutas y la logística utilizadas. En una de las causas se mencionó que el camino utilizado para el contrabando era conocido por todos y que ningún "ministro de S.M" había corregido este abuso."1 También el propio gobernador Miguel de Salcedo y Sierralta afirmaba en una carta al Cabildo que tenía noticias de esta ruta por la que comerciaban los vecinos de Santa Fe con los portugueses. ${ }^{12}$ Los funcionarios que debían "corregir" estos delitos eran quienes participaban de él y por ello, las comisiones se convirtieron en una intervención a las autonomías de las ciudades. Una de las primeras medidas tomadas por los comisionados fue el embargo de los oficios-excepto las alcaldías- a los involucrados en las causas porque su presencia en el ámbito de la toma de decisiones podía obstruir la investigación. Esto se hace manifiesto en diversas cartas de los comisionados a los gobernadores “... esta familia... en un año son parte y en otro año son Jueces... por lo que todas las demás familias de aquel vecindario viven ajadas y ultrajadas... ${ }^{13}$.

Los lazos de dependencia tendidos por estas elites con sus clientelas permitieron ejercer acciones de presión sobre ellas para influir en sus declaraciones, de este modo podían obstruir la investigación, formando verdaderos pactos de silencio. Esta fue una queja frecuente de los jueces comisionados a la autoridad superior:

...en esta participo a Usted como ejecuto dicha sumeria, con los testigos que discurro estarían hablados de parte del reo, 
debiéndose inferir se pondría solo lo dulce de sus declaraciones para que Usted en su vista no pudiese tomar la determinación conveniente para su Castigo' ${ }^{14}$.

También estos dichos denotan la importancia de la cercanía social del comisionado, que le permitió reconocer los testigos que podían formar parte de estas clientelas instruidas con los fines de obstruir la sumaria.

Pero estos jueces no sólo se enfrentan a lidiar con entramados de poder, sino también, con dificultades económicas que le impedían la apropiada ejecución de la comisión. Muchas quejas de los comisionados refieren que solventaban de su propio patrimonio los gastos de correos o el traslado a otras jurisdicciones cuando lo requería la investigación. Los adelantos para solventar los gastos necesarios de la comisión se relacionan con el prestigio que suponía "defender la persona [del Rey] y Real Jurisdicción que obtenía en crédito y honra de ella y de los Reflejos de la Majestad"15 y también con las expectativas sobre las futuras gracias esperadas por el buen desempeño como juez, "como Juez Comisionado de las cosas que los superiores han puesto a mi cuidado, por cuyas razones, por mi honra, por mis bienes embargados, me hallo con el no esperado premio de mi leal fidelidad"16. La gracia del rey era la recompensa que se esperaba por los servicios prestados en una sociedad cuyas relaciones se guiaban por el principio de reciprocidad. (Narotzky, 2002) Esta fue la vía fundamental de circulación de bienes y servicios que tendía a equilibrar el orden, respetando las jerarquías y desigualdades, y que consistía en "dar a cada uno lo que le pertenece", máxima de la cual dependía la armonía del cuerpo político.

Elinterés de los comisionados por alcanzar la recta administración de la justica se combinó con las expectativas de retribución real que, en ocasiones, llevó a comerte abusos en el uso de la jurisdicción delegada. Estos abusos se constituyeron en un argumento en contra de los comisionados por parte de las elites investigadas.

Los Exabruptos cometidos por Don Francisco Bracamonte auxiliado de la fuerza de que siempre se vale para motorizar sus arrojos y aterrorizar al Pueblo y sus habitadores con escandalosas resoluciones ofendiendo y menos Preciando Las Personas y oficios de los ministros del Rey Nuestro Señor en tal modo que el vulgo se persuade a que es Presidente de este Lugar ${ }^{17}$.

Otros de los argumentos en las acusaciones contra los comisionados fue la sustanciación de sumarias exageradamente extensas,

...que Don. Francisco de Bracamonte... pretende sacarnos las costas para cuyo fin que siempre le tiene tan presente ha hecho un volumen de auto temerario y no sólo pretende sacar las costas de los autos sino también declara que a costa nuestra. ${ }^{18}$.

Esta estrategia de alargar los pleitos permitía mayores réditos en beneficio del juez, teniendo en cuenta que sus emolumentos se descontaban de los costos del sumario. 
Todas estas acusaciones se convertían en causas judiciales, cuyo objetivo fue el de frenar la injerencia de las jurisdicciones superiores en el ámbito local. La promoción de varias causas judiciales o "empapelamiento judicial” (López Bejarano, 2016) se constituyó en una práctica usual para neutralizar al contrincante, fracción o en este caso el juez comisionado, que impedía el logro de intereses económicos o políticos. Otros motivos aludidos contra los comisionados giraron en torno a excesos cometidos en la toma de las declaraciones, el no ajustarse a las debidas formalidades del proceso, sumarias voluminosas o por el manejo fraudulento de los bienes embargados a los reos.

¿Cuáles fueron los motivos que impulsaron a dar curso al empapelamiento judicial de los comisionados encargados de limitar los excesos cometidos por las elites locales contra la Majestad? A pesar de los intentos por limitar las autonomías locales, la fuerte interdependencia entre la corona y sus súbditos americanos en la conservación de las posesiones ultramarinas, supuso diferentes grados de negociación política entre las elites locales y el poder real. No todas las acciones de estas elites locales fueron de abusos en la persecución de sus propios intereses. Los vecinos de Santa Fe fueron la línea medular en la defensa de la ruta comercial que conectaba el alto Perú con el puerto de Buenos Aires, como contención a los ataques y asaltos de los indígenas del Chaco por el norte y de los pampas desde el sur. Por otra parte, su contribución también fue fundamental en la frontera externa, con los dominios portugueses. reforzamiento de la defensa y para ello se creó un nuevo dispositivo militar, la compañía de blandengues. Esta unidad militar fue instituida por el gobernador Bruno Mauricio de Zavala; pero reclutada, comandada y sostenida por la ciudad de Santa Fe. Los vecinos debían proveer los caballos para la tropa y la carne por un año para alimentar a los soldados (Forconi, 2019). También en manos de los vecinos de la ciudad quedó la compra de armas, la dirección y ejecución de la construcción de fuertes y los aportes de caballos y provisiones para las milicias de la ciudad en las incursiones al valle calchaquí. Un ejemplo de ello fue la contribución de 100 caballos que realizó un acusado por contrabando, Ignacio de Barrenechea, para una de las entradas al valle calchaquí19 ${ }^{19}$ Otro de los investigados Estaban Marcos de Mendoza fue propuesto por el propio gobernador Zavala para comandar las milicias, en esa misma expedición, como cabo principal2o .

La defensa de los territorios americanos dependió del financiamiento de sus súbditos americanos y de la obligatoriedad al llamado de las armas de todos los vecinos, moradores y habitantes de todas las Provincias y jurisdicciones. La capacidad económica, la influencia en la vida política y militar de estos vecinos santafesinos demuestran el papel relevante que las elites americanas tuvieron en la conservación de los territorios. Esta relación de dependencia entre las elites americanas y la Corona, en muchas ocasiones, se constituyó en un motivo de peso en la "justa distribución de la justicia" a favor de las elites locales.

Hacia la década de 1720 el aumento de la conflictividad indígena en la frontera norte exigió el 


\section{Conclusiones}

Los casos judiciales presentados en este trabajo fueron las ventanas para observar las tensiones, en la composición policéntrica de la monarquía, entre las expectativas Reales y la autonomía de los grupos de poder locales. Los funcionarios e instituciones como Virreyes, Gobernadores y Audiencias, representantes del rey en los territorios americanos, hicieron uso del dispositivo de la justicia delegada para poner freno a los excesos de las elites locales sobre los intereses del Rey. La figura de los jueces comisionados y las negociaciones y acciones abiertas por las causas encomendadas, también permitieron matizar la imagen del debilitamiento de los cuerpos colegiados frente al avance del absolutismo Monárquico en el siglo XVIII. Esta cuestión se trasluce en la embestida judicial de las elites locales contra los jueces comisionados que lograron correr del medio a este agente y dejar sin efecto las acusaciones y sanciones por los delitos.

Las investigaciones sobre fraudes fiscales involucraron a miembros de la elite política de la ciudad, que tuvieron una fuerte presencia en el ámbito capitular. Por esta razón, se designaron jueces comisionados para la realización de las sumarias, en razón de que tuvieran una cierta distancia respeto de los intereses de estos grupos. Si bien esta distancia no fue de características geográficas -una persona ajena a la ciudad- estos comisionados estaban distanciados socialmente, es decir, que no tuvieron vínculos personales con los involucrados. Esta condición de distanciamiento permitía un mejor conocimiento de las tramas de relaciones de los involucrados en la causa y, por otra parte, era concebida como posibilidad de mayor equidad en la composición del orden social. La adopción de la justicia comisionada tuvo como objetivo sortear el entramado de intereses locales que controlaban el territorio, merced a la ocupación de los espacios de poder más relevantes de la ciudad. Otra de las razones fue dar mayor presencia a la mano Real en los distintos rincones que componían la monarquía. El comisionado era el "ministro fidedigno en quien reluce y reverbera el poderoso brazo de la Real Justicia"21 .

Los vecinos acusado era comerciantes, hacendados, funcionarios de la corona y contrabandistas y al mismo tiempo que eludían las imposiciones fiscales, se constituyeron en el brazo indispensable para el reforzamiento militar del territorio a partir de sus aportes económicos. Capitanes de milicia y de la compañía de dotación (los Blandengues de la frontera santafesina), jugaron un papel fundamental en el financiamiento de las campañas defensivas contra el indio, adelantando recursos que permitieron sostener el sitio de Santa Fe en su larga historia de conflicto fronterizo (Battcock, 2009; Battcock et.al, 2004; Lucaioli, 2015, 2014). Razones que hicieron difícil la sanción judicial sobre quienes fueron indispensables en la defensa territorial y la circulación comercial, frenando los ataques de las poblaciones no sometidas.

Las aspiraciones absolutistas por reforzar la autoridad real sobre los territorios americanos entraron en colisión con la trascendencia que estas elites tenían en la defensa de ellos, tanto en sus acciones militares como en sus aportes económicos. Una paradoja que suponía poner freno y sanciones a quienes evadían la fiscalidad, implicaba 
ir contra quienes contribuían en la conservación de los dominios del Rey. El restablecimiento del orden social implicó "la administración de la Real Justicia para Impartir los Reales auxilios, gracias, Mercedes y Castigos según los méritos de sus reales Vasallos"22 y son justamente los méritos militares de estos vasallos, el impedimento para la sanción de los delitos cometidos.

\section{Referencias citadas}

Agüero, A. A. (2005): “Ciudad y poder político en el Antiguo Régimen. La tradición castellana”, Cuadernos de historia, 15, pp. 127-163.

Albornoz Vásquez, Ma. E. (2015): “Autoridades locales conflictuadas: Temores y dificultades de jueces territoriales en Chile colonial (1711-1817)", Nuevo Mundo Mundos Nuevos. Disponible en web: https:// doi.org/10.4000/nuevomundo.68292

Barriera, D. G. (2002): Ensayos sobre microhistoria. Red Utopía-Jitanjáfora-Prohistoria.

Barriera, D. G. y Dalla Corte Caballero G., eds, (2003) Espacios de familia ¿Tejidos de lealtades o campos de confrontación? España y América, siglos XVI-XX. Morelia: Red Utopía-Jitanjáfora-Prohistoria.

Barriera, D. G. (2012): “Instituciones, justicias de proximidad y derecho local en un contexto reformista: Designación y regulación de" jueces de campo" en Santa Fe (Gobernación-Intendencia de Buenos Aires) a fines del siglo XVIII", Revista de historia del derecho, 44 , pp. 1-28.

Barriera, D. G. (2013): “Entre el retrato jurídico y la experiencia en el territorio. Una reflexión sobre la función distancia a partir de las normas de los Habsburgo sobre las sociabilidades locales de los oidores americanos", Caravelle, 101, pp. 133-54.

Barriera, D. G. (2014): "La historia de la justicia y las otras historias", en M. Bonaudo, y R. Jorba, eds, Historia Regional. Enfoques y articulaciones para complejizar una historia nacional, EDUNLP, pp. 19-39. Disponible en web: https://www.academia.edu/8303132/La_historia_de_la_justicia_y_las_otras_historias

Barriera, D.G. y Fradkin, R. (2014): Gobierno, justicias y milicias: La frontera entre Buenos Aires y Santa Fe:(17201830), FaHCE, Universidad Nacional de La Plata.

Barriera, D. y Forconi, Ma. C. (2015): "La compra de oficios como vía de acceso a las varas de justicia. Venalidad y coaliciones políticas en un cabildo rioplatense: La "casa de los Monje" (Santa Fe, 1700-1750)", El Taller de la Historia, 7 (7), pp. 255-305.

Barriera, D.G. (2017): “La política desde el campo: Iniciativas locales y gobierno rural en tiempos reformistas (Santa Fe, virreinato del Río de la Plata a finales del siglo XVIII)", Revista de Indias, 77 (270), pp. 521-549. Disponible en web: https://doi.org/10.3989/ revindias.2017.017

Battcock, C. (2009): "La frontera en tiempos de reformas. El fuerte de Melincué: Punto neurálgico en el sur santafesino", Estudios de Historia Novohispana, 41 (41), pp. 105-131.

Battcock, C., Gotta, C., y Manavella, A. (2004): “Frontera y poder: Milicias y misiones en la jurisdicción de Santa Fe de la Vera Cruz, 1700-1780. Algunas reflexiones”, 
Cuicuilco, 11 (30), pp. 1-22.

Bertrand, M. (2000): "Los modos relacionales de las élites hispanoamericanas coloniales: enfoques y posturas", Anuario IEHS, 15, pp. 61-80.

Bertrand, M., y Moutoukias, Z. (2002): Configuraciones y redes de poder: Un análisis de las relaciones sociales en América Latina. Caracas, Tropykos.

Birocco, C. M. (2011a): "En torno a la "anarquía” de 1714: La conflictividad política en Buenos Aires a comienzos del siglo XVIII", Anuario del Instituto de Historia Argentina, 11, pp. 73-98.

Birocco, C. M. (2011b): “La pesquisa de Mutiloa en Buenos Aires. Conformación de facciones y lucha de poder en el cabildo porteño (1700-1715)", en P. Polimene Autoridades y prácticas judiciales en el Antiguo Régimen. Problemasjurisdiccionales en el Río de la Plata, Córdobay Tucumán, Cuyo y Chile, Rosario, Prohistoria, pp. 33-56.

Boissevain, J. (1974): Friends of friends: Networks, manipulators and coalitions, Oxford, Blackwell.

Bott, E. (1990): Familia y red social: Roles, normas y relaciones externas en las familias urbanas corrientes, Madrid, Taurus.

Cárceles de Gea, B. (1994): Fraude y administración fiscal en Castilla: La Comisión de Millones (1632-1658): poder fiscal y privilegio jurídico-político. Banco de España, Servicio de Estudios.

Cárceles de Gea, B. (1995): "Del juez de comisión al comisario real (1632-1643)", Studia Historica. Historia
Moderna, 13, pp. 155-175.

Ceruti, M. (1998): “El mito de la omnisciencia y el ojo del observador", en P. Watzlawick, y P. Krieg, eds, El ojo del observador. Contribución al constructivismo. Homenaje a Heinz Von Foerster, Barcelona, Gedisa, pp. 32-59.

Chacón Jimenez, F. y Hernández Franco, J. (1992): Poder, familia y consanguinidad en la España del Antiguo Régimen, Barcelona, Anthropos.

Clavero, B. (1981): "Institución política y derecho: Acerca del concepto historiográfico de «Estado moderno»", Revista de estudios políticos, 19, pp. 43-58. Disponible en web: https://dialnet.unirioja.es/servlet/ articulo? codigo $=26645$.

Clavero, B. (1991): Antidora: Antropología católica de la economía moderna, Milán, Giuffrè Editore.

Clavero, B. (1993): “Debates historiográficos en la historia de las instituciones políticas”, en Sánchez Nistal et al., Problemas actuales de la historia, Salamanca, Universidad de Salamanca, pp. 199-210. Disponible en web: https://dialnet.unirioja.es/servlet/articulo?codigo $=914327$

Enríquez, L. (2016): "Los jueces diputados y los distritos judiciales borbónicos en Chile (1786-1818)", Revista chilena de derecho, 43 (2), pp. 643-668. Disponible en web: https://doi.org/10.4067/S0718-34372016000200012

Forconi, M. C. (2016): "Hacer política para hacer negocios. La política paraguaya, la política borbónica y los comerciantes de yerba en Santa Fe (Siglo XVIII)", Revista de Historia Americana y Argentina, 51 (1), pp. 
39-66. Disponible en web: http://revistas.uncuyo. edu.ar/ojs/index.php/revihistoriargenyame/article/ view/1240

Forconi, M. C. (2019): “Defensa, comercio y redes políticas: Santa Fe durante las primeras reformas borbónicas", Anuario IEHS, 34 (2), pp. 9-31. Disponible en web: http://www.fch.unicen.edu.ar/ojs-3.1.0/ index.php/anuario-ies/article/view/442

Garriga, C. (2004): "Orden jurídico y poder político en el Antiguo Régimen", Historia y derecho, historia del derecho - ISTOR, 16, pp. 1-21.

Garriga, C. (2012): “¿La cuestión es saber quién manda? Historia política, historia del derecho y "punto de vista"”, PolHis, 10, pp. 89-100.

Ginzburg, C. (1989): “Morelli, Freud y Sherlock Holmes: Indicios y Método Científico”, en U. Eco y T. A. Sebeok, eds, El signo de los tres. Dupin, Holmes, Peirce, Barcelona, Lumen, pp. 116-163.

Girón Zúñiga, N. (2015): Los jueces y el poder en el Norte Chico: Una aproximación a la trama política y económica de una sociedad en formación (1725-1790), Tesis de Maestría inédita, Universidad de Chile. Disponible en web: http://repositorio.uchile.cl/handle/2250/138605

Gómez González, I. (2011): “Más allá de la colegialidad. Una aproximación al juez de comisión en la España del Antiguo Régimen", Chronica nova: Revista de historia moderna de la Universidad de Granada, 37, pp. 21-40.

González Alonso, B. (2000): “Los procedimientos de control y exigencia de responsabilidad de los oficiales regios en el Antiguo Régimen (Corona de Castilla, siglos XIII-XVIII)", Anuario de la Facultad de Derecho de la Universidad Autónoma de Madrid, 4, pp. 249-272.

Gribaudi, M., ed, (1998): Espaces, temporalités, stratifications: Exercices méthodologiques sur les réseaux sociaux. París, l'Ecole des Hautes Etudes en Sciences Sociales.

Hespanha, A. M. (1989): Vísperas del leviatán: Instituciones y poder político (Portugal, siglo XVII), Madrid, Taurus.

Hespanha, A. M. (1994): “Las categorías de lo político y de lo jurídico en la época moderna”, Ius fugit: Revista interdisciplinar de estudios histórico-jurídicos, 3, pp. 63-100.

Imízcoz Beunza, J. M. (1996) Elites, poder y red social: las élites del País Vasco y Navarra en la Edad Moderna (estado de la cuestión y perspectivas), Bilbao, Universidad del País

Imízcoz Beunza, J. M. (2004) Casa, familia y sociedad :(País Vasco, Españay América, siglos XV-XIX), Bilbao, Universidad del País Vasco.

López Bejarano, P. (2016): “«Empapelar» al enemigo. El recurso a los procesos judiciales como Estrategia de acción política (Nueva Granada entre la colonia y República)", en E. Caselli, ed, Justicias, agentes y jurisdicciones. De la Monarquía Hispánica a los Estados Nacionales (Españay América, siglos XVI-XIX), Madrid, FCE, Red Columnaria, pp. 79-102.

Lucaioli, C. P. (2014): “Negociación y diplomacia en las fronteras del Chaco: Nuestra Señora de la Concepción de abipones", Historia e Cultura, 3 (2), pp. 380-405. 
Lucaioli, C. P. (2015): “Guerra y persuasión en las fronteras de Santa Fe: La gestión de Francisco Antonio de Vera Mujica (1743-1766)", Memoria americana, 23(1), pp. 99-128.

Molina, E. (2012): "Entre susurros y rumores: La fidelidad a la Monarquía y el delito de lesa majestad real en una ciudad periférica del Imperio español (Mendoza, 1782)", Revista de historia del derecho, 44, pp. 128-148.

Molina, E. (2014): "La construcción cotidiana de legitimidad: Atentados contra jueces y abusos de autoridad en una jurisdicción periférica de la Monarquía española. Mendoza, 1770-1810”, Prohistoria, 21, pp. 85-103.

Moutoukias, Z. (1988): “Burocracia, contrabando y autotransformación de las elites. Buenos Aires en el siglo XVII", Anuario IEHS, 3, pp. 213-248.

Moutoukias, Z . (1995): “Narración y análisis en la observación de vínculos y dinámicas sociales: El concepto de red personal en la historia social y económica", en M. Bjerg y H. Otero, eds, Inmigración y redes sociales en la Argentina moderna, Tandil, CEMLA-IEHS, pp. 221-241.

Moutoukias, Z. (2000): "Familia patriarcal o redes sociales: Balance de una imagen de la estratificación social”, Anuario IEHS, 15, pp. 133-151.

Ponce Leiva, P. y Amadori, A. (2008): “Historiografía sobre élites en la América Hispana: 1992-2005”, Nuevo Mundo Mundos Nuevos. Disponible en web: http:// journals.openedition.org/nuevomundo/38773

Narotzky, S. (2002): “Reivindicación de la ambivalencia teórica: la reciprocidad como concepto clave", Endoxa: Series filosóficas, 15, pp. 15-32.

Revel, J., ed, (1996): Jeux d'échelles: La micro-analyse à l'expérience, París, Coédition Gallimard.

Sanjurjo de Driollet, I. (2016): "Cabildo, agentes reales y conflictos jurisdiccionales en una ciudad periférica de la Monarquía española. Mendoza, siglo XVIII", Antítesis, 9(17), pp. 176-199.

Tarragó, G. (2006): “La Reformas Borbónicas”, en D. Barriera, Nueva historia de Santa Fe, Rosario, Prohistoria- La Capital, pp. 115-43.

Tarragó, G. (2012b): “The long kiss goodbye: Santa Fe and the conflict over the privilege of Puerto Preciso (1726-1743)”, en G. De Luca y G. Sabatini, eds, Growing in the Shadow of an Empire. How Spanish Colonialism Affected Economic Development in Europe and in the World (XVI th-XVIII th cc.), Milano, Franco Angeli, pp. 271-84.

Zorraquín Becú, R. La organización judicial argentina en el período hispánico, Buenos Aires, Perrot, 1981.

\section{Fuentes}

Archivo General de la Nación (AGN), Sala IX, Tribunales y Tomo 3-10-7.

Archivo General de la Provincia de Santa Fe (AGSF) Actas Capitulares (AC).

Castillo de Bobadilla, J. (1775): Política para corregidores y señores de vasallos, Madrid, Imprenta de la Gazeta. Tomo I, Lib. II. 
Recopilación de Leyes de los Reinos de las Indias, Libro VII.

*Agradezco mucho los valiosos y dedicados comentarios de los evaluadores que contribuyeron a mejorar este trabajo.

\section{Notas}

${ }^{1}$ Como señala Barriera, (2019: 220) "En cuanto al vocablo "funcionario", que se ha impuesto por el uso, no es completamente erróneo si se considera que hace referencia a quien ejercía una función de gobierno o justica."

${ }^{2}$ Dos trabajos pioneros en esta metodología (Boissevain, 1974; Bott, 1990).

${ }^{3}$ Algunos trabajo clásicos de referencia (Bertrand y Moutoukias, 2002; Chacón Jiménez y Hernández Franco, 1992; Gribaudi, 1998; Revel, 1996).

4Felipe V elaboró una agenda de reformas en las áreas de gobierno, de administración, de lo militar y de hacienda, conformada por cinco secretarías, de Estado; Gracia y Justicia; Hacienda; Guerra y Marina e Indias. La nueva estructura administrativa más especializada buscaba una comunicación más directa y expeditiva con el rey a través del "despacho de boca" y la "vía reservada". Este estilo de gobierno privilegiaba la comunicación directa del rey con nuevas élites en la decisión política, erosionando el poder de los antiguos consejos. (López Cordón, 2000; Guerrero Elecalde, 2012; Dougnac Rodríguez, 1994; Andújar Castillo, 2001, 2004; Tau Anzoátegui, 1999; Santos
Martínez, 1999).

${ }^{5} \mathrm{La}$ dependencia del rey respecto a las elites de poder americanas en cuanto a la defensa de sus dominios construyó relaciones de poder -entre el rey y sus reinos americanos- que se concretaron sobre la base de equilibrios cambiantes entre los grados de autonomía de las ciudades y las exigencias del poder Real.

61740. Francisco Antonio de Vera Mujica, Manuel Francisco de Gaete, Ignacio de Barrenechea, Felipe Portillo y Tomás Figueroa por sospechas de haber tenido comercio ilícito de mulas con los Portugueses. AGN. Sala IX, Tribunales Leg. 293, Exp. 5, f.76 (para esta investigación se designa como comisionado al Regidor decano Juan de Zevallos)

${ }^{7}$ Sta Fe 2 de mayo de 1716, AGSF. AC. T. VII, f. 277.

8Isabel de Pessoa con Francisco Bracamonte sobre herencia (1714). DEEC, SF, EC, t. 21, leg.93, f.114-137

${ }^{9}$ Como mencionamos anteriormente, desde los Reyes Católicos se recurrió a la figura de las comisiones judiciales como freno y control de las elites locales. Esta cuestión perdura a la largo de los siglos como lo demuestra su mención en el tratado de Castillo de Bobadilla a finales del XVI, recurso al que se echa mano hasta el siglo XVIII.

${ }^{10}$ Carta de Francisco de Bracamonte al Gobernador Bruno Mauricio de Zavala sobre comisión del Virrey AGN.T. 3-10-7. Sta Fe 23 de septiembre de 1725.

111740- Francisco Antonio de Vera Mujica, Manuel Francisco de Gaete, Ignacio de Barrenechea, Felipe Portillo y Tomás Figueroa por sospechas de haber 
tenido comercio ilícito de mulas con los Portugueses. AGN. Sala IX, Tribunales Leg. 293, Exp. 5, f.3 y f. 29.

${ }^{12}$ Sta Fe 22 de abril de 1741, AGSF. AC. T. XI, f. 39 y 39v.

131740-Investigación sobre unas haciendas de mulas y caballos que se enviaron desde Santa Fe hacia Colonia de Sacramento. AGN, Sala IX, Tribunales, Leg. G-6, Exp. 2, f. 313.

${ }^{14}$ Carta de Francisco de Bracamonte al gobernador Bruno Mauricio de Zavala AGN.T. 3-10-7. Sta Fe 16 de febrero de 1725.

${ }^{15}$ Sta Fe 29 de agosto de 1727. AGSF. AC. T IX, f. 406v.

161740-Investigación sobre unas haciendas de mulas y caballos que se enviaron desde Santa Fe hacia Colonia de Sacramento. AGN, Sala IX, Tribunales, Leg. G-6, Exp. 2, f. 153.

${ }^{17}$ Carta del cabildo de Santa Fe al gobernador Bruno Mauricio de Zavala. Sta Fe 29 de agosto de 1727 AGSF. AC. T IX, f. 408.

${ }^{18}$ Carta de Juan Joseph de Lacoizqueta al gobernador Bruno Mauricio de Zavala. Tomo 3-10-7. Sta Fe 13 de agosto de 1725.

${ }^{19}$ Sta Fe 23 de abril de 1728. AGSF. AC. Carp nro 14A, f $54 \mathrm{v}$ a $55 \mathrm{v}$.

${ }^{20}$ Sta Fe 15 de enero 1728. AGSF. AC. Carp nro 14A, f 8 yv.

211740- Investigación sobre unas haciendas de mulas y caballos que se enviaron desde Santa Fe hacia Colonia de Sacramento. AGN, Sala IX, Tribunales, Leg. G-6, Exp. 2, f. 174v.

221740-Investigación sobre unas haciendas de mulas y caballos que se enviaron desde Santa Fe hacia Colonia de Sacramento. AGN, Sala IX, Tribunales, Leg. G-6, Exp. 2, f. 155. 